\title{
Contributions of Proximate Determinants to Fertility Transition in Bangladesh: An Analysis of Bongaarts' Fertility Model
}

\author{
Iqramul Haq ${ }^{1 *}$, Mahabub Alam², Injamul Haq Methun ${ }^{3}$ \\ ${ }^{1}$ Department of Agricultural Statistics, Sher-e-Bangla Agricultural University, Dhaka, Bangladesh \\ ${ }^{2}$ Bangladesh Bureau of Statistics (BBS), Statistics and Informatics Division, Ministry of Planning, Dhaka, Bangladesh \\ ${ }^{3}$ Department of Statistics, Jagannath University, Dhaka, Bangladesh
}

Corresponding Author: Iqramul Haq, Lecturer, Department of Agricultural Statistics, Sher-e-Bangla Agricultural University, Dhaka-1207, Bangladesh. Tel: +880-1715331220, Email: shimuljnu107046@gmail.com

Received November 10, 2018; Accepted February 10, 2019; Online Published March 4, 2019

\begin{abstract}
Introduction: Fertility transition is outright by prime four proximate determinants (marriage, contraception, postpartum infecundability, and abortion). The present study examines the contributions of proximate determinants on fertility decline and quantifies inhibiting the effect of major proximate determinants according to the socioeconomic characteristics in Bangladesh.

Methods: The current study was based mainly on the three Bangladesh Demographic and Health Surveys (BDHSs) carried out in 19931994, 2004, and 2014. Bongaarts' fertility framework was applied to analyze the proximate determinants of fertility in the socioeconomic status of women in Bangladesh.

Results: In 1993-1994, contraception was the greatest impediment to fertility followed by postpartum infecundability, marriage, and induced abortion, respectively. In 2014, contraception was the highest fertility obstructing effect followed by marriage, postpartum infecundability, and abortion, respectively, in both rural and urban areas of Bangladesh. Throughout the study period and even now, fertility is revered in the Sylhet and Chittagong divisions of Bangladesh. The fertility-inhibiting effect of marriage, contraception, and abortion has an affirmative relationship with the educational status of women. Postpartum infecundability, however, displays an inverse relationship with the educational status of women.

Conclusion: The current study suggests that contraception plays a vital role in fertility reduction in Bangladesh. In particular, special attention should be placed on those regions (Chittagong and Sylhet divisions) that register low contraception prevalence rates. Special programs should focus on creating an awareness of the disadvantages of child marriage among women who reside in the division of Chittagong and Sylhet of Bangladesh.

Keywords: Fertility, Proximate Determinants, Postpartum Infecundability, Abortion
\end{abstract}

Citation: Haq I, Alam M, Methun IH. Contributions of proximate determinants to fertility transition in Bangladesh: an analysis of Bongaarts' fertility model. Int J Travel Med Glob Health. 2019;7(1):23-32. doi:10.15171/ijtmgh.2019.06.

\begin{abstract}
Introduction
The world's population had reached 7.6 billion as of mid2017, and it is expected to rise by 1 billion people over the next 12 years. ${ }^{1}$ According to the projections of the medium variant, the population of Bangladesh will increase 37 million, from 165 million people in 2017 to 202 million in $2050 .{ }^{1}$ Bangladesh is the 8th most populous country in the world, ${ }^{1}$ and the total fertility rate (TFR) is now 2.2 births per women. In 2014, the Bangladesh Demographic and Health Survey (BDHS) revealed that the TFR is 2.3 children per woman, which is equivalent to the 2011 BDHS. ${ }^{2}$ In 6 out of 7 divisions in Bangladesh, fertility decreased or remained the same during the last two BDHS surveys (2011 and 2014). ${ }^{2}$
\end{abstract}

In last two surveys, TFR was slightly increased in Dhaka division. ${ }^{2}$ Khulna and Rangpur had the same fertility rate in the last two BDHSs. ${ }^{2}$ In 2014, the BDHS revealed that Khulna and Rangpur divisions had already crossed below the replacement fertility level (TFR $=1.9$ ), while Rajshahi division and Barisal division are near replacement fertility (2.1 and 2.2 births per woman, respectively). ${ }^{2}$ In 2014, the BDHS showed that women's education and the wealth status is negatively associated with fertility; i.e. as the education level increased, fertility declined, and the same was true for the wealth status. ${ }^{2}$

In Bangladesh, fertility declined predominantly because of the successful implementation of family planning. . $^{3-6}$ Several studies conducted in Ethiopia and Zambia found

Copyright $\odot 2019$ The Author(s). This is an open-access article distributed under the terms of the Creative Commons Attribution License (http:// creativecommons.org/licenses/by/4.0), which permits unrestricted use, distribution, and reproduction in any medium, provided the original work is properly cited. 
that natural fertility was predominantly obstructed through to the marriage and postpartum infecundability, ${ }^{7,8}$ while contraceptive practice was a key factor in the decline in fertility in Bangladesh. ${ }^{9}$ The use of effective contraceptive methods and economic status have played vital roles in fertility transition. ${ }^{10}$ Age at marriage and abortion have also been crucial in reducing fertility among Asian women. ${ }^{11}$ The cause of the decline in fertility was not related to level of prosperity, and that the way it will chase is not compulsorily measured by socioeconomic factors. ${ }^{12-14}$

Researchers have found that fertility declines sharply with socio-economic development. ${ }^{13,15}$ Human reproduction is an intricate process, which is regulable by socioeconomic and demographic factors and related to a number of biological, behavioral, and cultural factors. ${ }^{16,17}$ Conversely, proximate determinants applies outright impacts on fertility fluctuation. ${ }^{7,18,19}$ If one proximate determinant changes, fertility is changed necessarily by the other proximate determinants remaining constant. ${ }^{16,17,20}$ Several researchers have observed that background factors are likely to influence the proximate determinants of fertility. ${ }^{16,21}$

The prime goal of this study was to identify the contribution of proximate factors on fertility transition in Bangladesh. The relative effects of marriage patterns, contraceptive use, abortion practice, and postpartum infecundability on fertility were found to be associated with socioeconomic characteristics in Bangladesh using data from the three BDHSs conducted in 1993-1994, 2004, and 2014 and applying Bongaarts' Proximate Determinants model.

\section{Methods}

The study was carried out on secondary data adopted from the first, fourth, and seventh programs of the BDHS (19931994, 2004, and 2014). All the surveys were administered by the Bangladesh Bureau of Statistics (BBS) and are nationally representative. All surveys except the 2014 BDHS comprised successful interviews with women aged 10-49 and were based on a two-stage stratified sample of households. In the first stage, 304 and 361 primary sampling units were selected in the 1993-1994 and 2004 BDHSs, respectively. ${ }^{22,23}$ Six hundred enumeration areas (EAs) were selected with probability proportional to the EA size in the 2014 BDHS. $^{2}$ For the purpose of the study, data was collected on evermarried women aged 15-49 years. In the 1993-1994, 2004, and 2014 BDHSs, 9495, 11290, and 17863 ever-married women aged 15-49 were successfully interviewed. ${ }^{22,23}$ To quantify the inhibition of fertility due to the major proximate determinants according to the socioeconomic characteristics in Bangladesh, Bongaarts' Proximate Determinants model was applied. The Statistical Package for Social Sciences (SPSS) version 23 software was used for data processing and analyses.

\section{Bongaarts' Proximate Determinants Model}

Bongaarts' aggregate model examines the relationship between TFR and proximate determinants of fertility. ${ }^{16,17}$ Bongaarts' model observed that four major proximate determinants had the highest variation of fertility: marriage, contraception, induced abortion, and postpartum infecundability, and those indices are denoted by $\mathrm{Cm}, \mathrm{Cc}, \mathrm{Ca}$, and $\mathrm{Ci}$, respectively. Bongaarts' model is as follows:

$\mathrm{TFR}=\mathrm{Cm} \times \mathrm{Cc} \times \mathrm{Ca} \times \mathrm{Ci} \times \mathrm{TF}$

where, $\mathrm{Cm}=$ index of marriage,

$\mathrm{Cc}=$ index of contraception,

$\mathrm{Ca}=$ index of abortion,

$\mathrm{Ci}=$ index of postpartum infecundability,

$\mathrm{TF}=$ Total Fecundity, and

TFR=Total fertility rate.

The estimated value of each index ranged from 0 to 1 , with 0 indicating a greater inhibition of fertility and 1 indicating a lower inhibiting effect. Bongaarts' model showed that the value of TF ranged between 13 and 17 births per women, but the average value of TF all over the world is $15.3 .^{20}$

Bongaarts' aggregate fertility model from equation (1) becomes:

$\mathrm{TFR}=\mathrm{Cm} \times \mathrm{Cc} \times \mathrm{Ca} \times \mathrm{Ci} \times 15.3$

The Index of Marriage

The estimated value of the marriage variable $(\mathrm{Cm})$ is the ratio of TFR to total marital fertility rate (TMFR):

$C m=\frac{T F R}{T M F R}$

The Index of Contraception

The estimated value of contraception (Cc) was calculated as: $\mathrm{Cc}=1-1.08 \times \mathrm{u} \times \mathrm{e}$

where $\mathrm{u}$ is the prevalence of current contraceptive use among married women aged 15 to 49 years and e is the weighted average use - effectiveness of contraceptive with the constant 1.08 as an adjustment factor.

The Index of Induced Abortion

The estimated value of induced abortion $(\mathrm{Ca})$ was obtained as:

$\mathrm{Ca}=\mathrm{TFR} /(\mathrm{TFR}+0.4 \times(1+\mathrm{u}) \times \mathrm{TA})$

The abortion rate was calculated in a manner similar to that of age-specific fertility rate, but here, the denominator was the number of abortions in the last year among pregnant women rather than the number live births in the last year.

Therefore, the value of total abortion was calculated by:

$\mathrm{TA}=5 *$ ASAR

The Index of Postpartum Infecundability

The estimated value of postpartum infecundability (Ci) was calculated as:

$C i=\frac{20}{(18.5+i)}$

where $\mathrm{i}=$ mean duration of postpartum infecundability through to the breastfeeding or postpartum abstinence.

\section{Mean duration $(i)=\sum p_{i} \times w_{i}$}

where $\mathrm{p}_{\mathrm{i}}$ is the proportion insusceptible for the first group, and $w i$ is the time interval between midpoint value of the current group and the preceding group. 
Importance of the Fertility-Inhibiting Effect Being Accounted for Each Proximate Variables

The fertility-obstructing effect of each proximate determinate was calculated by the ratio of the differences between TF and estimated TFR, with the product of the logarithm of each index to the sum of the logarithm of all indices of proximate variables. ${ }^{24}$

Effect of marriage $=\frac{[\text { TF-TFR(estimated) }] \times \log _{e} C_{m}}{\log _{e} C_{m}+\log _{e} C_{c}+\log _{e} C_{i}+\log _{e} C_{a}}$

Effect of contraception $=\frac{[\text { TF-TFR(estimated) }] \times \log _{e} C_{c}}{\log _{e} C_{m}+\log _{e} C_{c}+\log _{e} C_{i}+\log _{e} C_{a}}$

Effect of induced abortion $=\frac{[\text { TF-TFR(estimated })] \times \log _{e} C_{a}}{\log _{e} C_{m}+\log _{e} C_{c}+\log _{e} C_{i}+\log _{e} C_{a}}$

Effect of postpartum infecundability $=\frac{[\text { TF-TFR(estimated) }] \times \log _{e} C_{i}}{\log _{e} C_{m}+\log _{e} C_{c}+\log _{e} C_{i}+\log _{e} C_{a}}$

\section{Results}

Residence

Table 1 shows the changes in the indices of all proximate factors on fertility variations according to residence in Bangladesh from the 1993-1994 to 2014 BDHSs. As can be seen, marriage had the highest significant effect on fertility changes in rural areas as compared with urban areas. The average value of $\mathrm{Cm}$ was 0.729 (accounting for $27.1 \%$ of the fertility reduction) in the given study periods.

The contraception index had the highest in rural areas (0.575 in 1993-1994, 0.443 in 2004, and 0.387 in 2014) compared with urban areas (0.473 in 1993-1994, 0.389 in 2004, and 0.354 in 2014). In rural areas, Cc decreased about 0.188 points from $1993-1994$ to 2014 , while it decreased 0.119 points in urban areas in the same period. The inhibition effect of abortion was greater in urban areas than among sexually active women in rural areas. The abortion index values for women residing in rural areas was 0.952 in 1993-1994, 0.917 in 2004, and 0.927 in 2014, whereas the same values in urban areas were 0.920 in $1993-1994,0.874$ in 2004 , and 0.899 in 2014 (Table 1).
In terms of postpartum infecundability, the estimated values of the $\mathrm{Ci}$ index in rural areas were 0.646 in 1993-1994, 0.706 in 2004, and 0.750 in 2014, while in urban regions, these values were 0.677 in $1993-1994,0.753$ in 2004 , and 0.772 in 2014 (Table 1). This implies that the controlling effect of postpartum infecundability was highest in rural areas (29.9\%) compared with urban areas. During the study period, contraception had the most significant fertility-inhibiting effect among all proximate determinants in both urban and rural areas of Bangladesh.

\section{Division}

Table 2 reveals the changes in the indices of all proximate factors on fertility variations according to the divisions of Bangladesh from the 1993-1994, 2004, and 2014 BDHSs. In the 1993-1994 BDHS, Bangladesh was partitioned into five major administrative divisions, but in the 2014 BDHS Bangladesh was partitioned into seven major administrative divisions. In 2014, marriage had the most important effect in Rangpur division with an index value of 0.651 (34.9\% reduction in fertility). In the three studied survey periods, marriage had the highest controlling effect on fertility reduction in Rajshahi division compared to all other divisions, with a mean $\mathrm{Cm}$ index value of 0.744 (25.6\% reduction in fertility). Following Rajshahi, the effect of marriage was significant in the Khulna divisions, with a mean $\mathrm{Cm}$ index value of 0.748 and, to some extent, in the Dhaka (mean value of Cm was 0.769 ) and Barisal (average index value was 0.773 ), Sylhet (mean $\mathrm{Cm}$ value was 0.784), and Chittagong divisions (mean Cm value was 0.788).

Contraception had the highest fertility-inhibiting effect of all proximate variables in Bangladesh. A similar picture emerged when regional variations in fertility in Bangladesh were considered. Table 2 shows that the continuous increasing trend of contraceptive use was a fertility inhibitor in almost all divisions in Bangladesh during the three studied surveys. In 2014, the fertility-inhibiting effect of contraception was highest (70.4\% fertility reduction) in Rangpur division and lowest in Sylhet division. Contraception had the highest

Table 1. Variations of the Proximate Determinants on Fertility Changes According to Selected Residence of Bangladesh: $1993-1994$ to 2014 BDHS

\begin{tabular}{|c|c|c|c|c|c|}
\hline \multirow{2}{*}{$\begin{array}{l}\text { Residence and Survey } \\
\text { Years }\end{array}$} & \multicolumn{4}{|c|}{ Proximate Determinants } & \multirow[b]{2}{*}{ TFR } \\
\hline & $\begin{array}{c}\mathrm{Cm} \text { (Percentage of Fertility } \\
\text { Reduction) }\end{array}$ & $\begin{array}{l}\text { Cc (Percentage of } \\
\text { Fertility Reduction) }\end{array}$ & $\begin{array}{l}\text { Ca (Percentage of } \\
\text { Fertility Reduction) }\end{array}$ & $\begin{array}{c}\text { Ci (Percentage of Fertility } \\
\text { Reduction) }\end{array}$ & \\
\hline 1993-1994 & $0.798(20.2 \%)$ & $0.473(52.7 \%)$ & $0.920(8.0 \%)$ & $0.677(32.3 \%)$ & 3.60 \\
\hline 2004 & $0.719(28.1 \%)$ & $0.389(61.1 \%)$ & $0.874(12.6 \%)$ & $0.753(24.7 \%)$ & 2.82 \\
\hline 2014 & $0.716(28.4 \%)$ & $0.354(64.6 \%)$ & $0.899(10.1 \%)$ & $0.772(22.8 \%)$ & 2.69 \\
\hline \multicolumn{6}{|l|}{ Rural } \\
\hline 1993-1994 & $0.752(24.8 \%)$ & $0.575(42.5 \%)$ & $0.952(4.8 \%)$ & $0.646(34.5 \%)$ & 4.07 \\
\hline 2004 & $0.729(27.1 \%)$ & $0.443(55.7 \%)$ & $0.917(8.3 \%)$ & $0.706(29.4 \%)$ & 3.20 \\
\hline 2014 & $0.705(29.5 \%)$ & $0.387(61.3 \%)$ & $0.927(7.3 \%)$ & $0.750(25.0 \%)$ & 2.90 \\
\hline \multicolumn{6}{|l|}{ Total } \\
\hline 1993-1994 & $0.756(24.4 \%)$ & $0.566(43.4 \%)$ & $0.942(5.8 \%)$ & $0.649(35.1 \%)$ & 4.00 \\
\hline 2014 & $0.708(29.2 \%)$ & $0.384(61.6 \%)$ & $0.900(10.0 \%)$ & $0.754(24.6 \%)$ & 2.82 \\
\hline
\end{tabular}

Abbreviation: TFR, total fertility rate. 
Table 2. Variations of the Proximate Determinants on Fertility Changes according to the Divisions of Bangladesh: 1993-1994 to 2014 BDHS

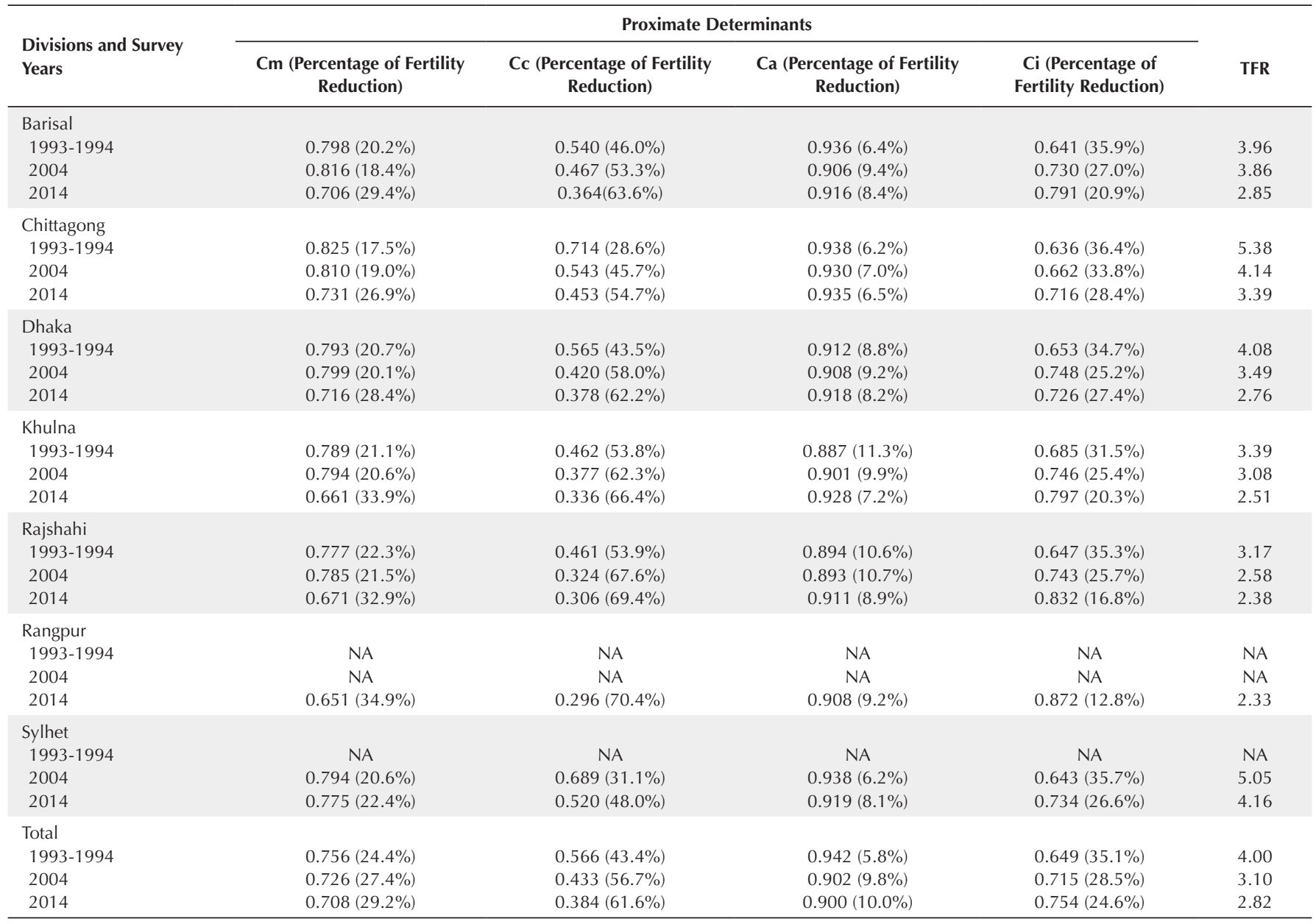

Abbreviation: TFR, total fertility rate; NA, not applicable.

crucial effect in Rajshahi division compared with all other divisions, having a mean Cc value of 0.364 (63.6\% of fertility reduction) during the studied survey periods (Table 2). Following Rajshahi division, the effect of contraception was significant in Khulna division, with an average index value of 0.392 (60.8\% reduction in TN relative to TMFR) and partially in Dhaka (mean Cc value was 0.454) and Barisal (mean Cc value was 0.457 ) divisions. Its importance was less significant in the Sylhet and Chittagong divisions.

The inhibition effect of abortion was greatest in Rajshahi division (0.899), followed by Khulna (0.905), Rangpur (0.908), Dhaka (0.913), and Barisal (0.919) divisions, and its importance was less significant in Sylhet and Chittagong divisions (Table 2). The controlling effect of postpartum infecundability to fertility showed a continuously decreasing trend in almost all divisions in Bangladesh during the three studied surveys.

\section{Women's Education}

Table 3 presents the changes in the indices of all proximate factors on fertility variations according to the educational status of women in Bangladesh in the 1993-1994, 2004, and 2014 BDHSs. Marriage was the most important proximate determinant of fertility change among women with a secondary or higher education. The $\mathrm{Cm}$ value was 0.719 in
1993-1994, 0.712 in 2004, and 0.701 in 2014. Marriage had the most important fertility-inhibiting effect among women with a secondary or higher education compared with their counterparts; the mean value of $\mathrm{Cm}$ during the three studied surveys was 0.711 (28.9\% reduction in fertility).

Among women who had completed a primary education, the Cc value showed a falling trend in all survey periods (0.553 in 1993-1994, 0.410 in 2004, 0.364 in 2014). To be more precise, Cc declined about 34.2\% between 1993-1994 and 2014. The Cc value also showed a decreasing tendency among women who were educated (secondary or higher education), with a value of 0.463 in 1993-1994, which fell by about $12.5 \%$ to 0.405 in 2004 and fell by a further $13.1 \%$ to 0.352 in 2014 (Table 3). Among all proximate determinants, contraception had the highest role in reducing fertility among women who had completed a secondary or higher education (mean index score was 0.407 ) compared with women with no education (mean Cc score was 0.471).

Abortion had the greatest fertility-inhibiting effect for women who had completed a secondary or higher education, with an average index value of $0.895 \quad(10.5 \%$ fertility reduction) during the studied periods. The inhibition effect of postpartum infecundability decreased with increases in educational attainment. The inhibiting effect of postpartum infecundability among women with no education showed 
Table 3. Variations in Proximate Determinants on Fertility Changes according to Women's Education in Bangladesh: 1993-1994 to 2014 BDHS

\begin{tabular}{|c|c|c|c|c|c|}
\hline \multirow{2}{*}{$\begin{array}{l}\text { Women's Education and } \\
\text { Survey Years }\end{array}$} & \multicolumn{4}{|c|}{ Proximate Determinants } & \multirow[b]{2}{*}{ TFR } \\
\hline & $\begin{array}{l}\text { Cm (Percentage of } \\
\text { Fertility Reduction) }\end{array}$ & $\begin{array}{c}\text { Cc (Percentage of Fertility } \\
\text { Reduction) }\end{array}$ & $\begin{array}{l}\text { Ca (Percentage of } \\
\text { Fertility Reduction) }\end{array}$ & $\begin{array}{l}\mathrm{Ci} \text { (Percentage of } \\
\text { Fertility Reduction) }\end{array}$ & \\
\hline \multicolumn{6}{|l|}{ No Education } \\
\hline 1993-1994 & $0.790(21.0 \%)$ & $0.595(40.5 \%)$ & $0.922(7.8 \%)$ & $0.625(37.5 \%)$ & 4.14 \\
\hline 2004 & $0.792(20.8 \%)$ & $0.436(56.4 \%)$ & $0.929(7.1 \%)$ & $0.670(33.0 \%)$ & 3.29 \\
\hline 2014 & $0.749(25.1 \%)$ & $0.381(61.9 \%)$ & $0.931(6.9 \%)$ & $0.742(25.8 \%)$ & 3.03 \\
\hline \multicolumn{6}{|l|}{ Primary } \\
\hline 1993-1994 & $0.799(20.1 \%)$ & $0.553(44.7 \%)$ & $0.906(9.4 \%)$ & $0.674(32.6 \%)$ & 4.12 \\
\hline 2004 & $0.765(23.5 \%)$ & $0.410(59.0 \%)$ & $0.911(8.9 \%)$ & $0.720(28.0 \%)$ & 3.15 \\
\hline 2014 & $0.735(26.5 \%)$ & $0.364(63.6 \%)$ & $0.922(7.8 \%)$ & $0.750(25.0 \%)$ & 2.98 \\
\hline \multicolumn{6}{|l|}{ Secondary } \\
\hline 1993-1994 & $0.719(28.1 \%)$ & $0.463(53.7 \%)$ & $0.880(12.0 \%)$ & $0.702(29.8 \%)$ & 3.15 \\
\hline 2004 & $0.712(28.8 \%)$ & $0.405(59.5 \%)$ & $0.889(11.1 \%)$ & $0.728(27.2 \%)$ & 2.86 \\
\hline 2014 & $0.701(29.9 \%)$ & $0.352(64.8 \%)$ & $0.915(8.5 \%)$ & $0.761(23.9 \%)$ & 2.63 \\
\hline \multicolumn{6}{|l|}{ Total } \\
\hline 1993-1994 & $0.756(24.4 \%)$ & $0.566(43.4 \%)$ & $0.942(5.8 \%)$ & $0.649(35.1 \%)$ & 4.00 \\
\hline 2004 & $0.726(27.4 \%)$ & $0.433(56.7 \%)$ & $0.902(9.8 \%)$ & $0.715(28.5 \%)$ & 3.10 \\
\hline 2014 & $0.708(29.2 \%)$ & $0.384(61.6 \%)$ & $0.900(10.0 \%)$ & $0.754(24.6 \%)$ & 2.82 \\
\hline
\end{tabular}

a declining trend (0.625 in 1993-1994, 0.670 in 2004, and 0.742 in 2014) compared to that of women with a primary level education (0.674 in 1993-1994, 0.720 in 2004, and 0.750 in 2014) and women with a secondary or higher education (0.702 in 1993-1994, 0.728 in 2004, and 0.761 in 2014). On women who had completed a secondary or higher education, contraception and marriage had the greatest fertilityinhibiting effects between 1993-1994 and 2014. The TFR declined from 3.15 children per woman

Women's Economic Status

Table 4 presents variations in the proximate determinants on fertility changes according to the economic status of women in Bangladesh. The fertility-inhibiting effect of marriage was observed among women from the poorest households (0.809 in 1993-1994, 0.779 in 2004, and 0.805 in 2014) and those from the richest households in Bangladesh (0.720 in 1993-1994, 0.716 in 2004, and 0.710 in 2014) (Table 4). Among all proximate determinants, contraception had the highest fertility-reducing effect among the richest women in Bangladesh (0.491 in 1993-1994 to 0.345 in 2014) compared with the poorest women (0.592 in 1993-1994 to 0.396 in 2014). More precisely, the reduction in fertility through contraception was highest among the richest women (almost

Table 4. Variations in the Proximate Determinants on Fertility Changes according to the Wealth Status of Women in Bangladesh: 1993-1994 to 2014 BDHS

\begin{tabular}{|c|c|c|c|c|c|}
\hline \multirow{2}{*}{$\begin{array}{l}\text { Women's Wealth Status and } \\
\text { Survey Years }\end{array}$} & \multicolumn{4}{|c|}{ Proximate Determinants } & \multirow{2}{*}{ TFR } \\
\hline & $\begin{array}{c}\mathrm{Cm} \text { (Percentage of Fertility } \\
\text { Reduction) }\end{array}$ & $\begin{array}{l}\text { Cc (Percentage of } \\
\text { Fertility Reduction) }\end{array}$ & $\begin{array}{l}\text { Ca (Percentage of } \\
\text { Fertility Reduction) }\end{array}$ & $\begin{array}{l}\mathrm{Ci} \text { (Percentage of } \\
\text { Fertility Reduction) }\end{array}$ & \\
\hline \multicolumn{6}{|l|}{ Poorest } \\
\hline 1993-1994 & $0.809(19.1 \%)$ & $0.592(40.8 \%)$ & $0.933(6.7 \%)$ & $0.625(37.5 \%)$ & 4.27 \\
\hline 2004 & $0.779(22.1 \%)$ & $0.470(53.0 \%)$ & $0.937(6.3 \%)$ & $0.679(32.1 \%)$ & 3.56 \\
\hline 2014 & $0.805(19.5 \%)$ & $0.396(60.4 \%)$ & $0.942(5.8 \%)$ & $0.753(24.7 \%)$ & 3.44 \\
\hline \multicolumn{6}{|l|}{ Poorer } \\
\hline 1993-1994 & $0.804(19.6 \%)$ & $0.587(41.3 \%)$ & $0.928(7.2 \%)$ & $0.622(37.8 \%)$ & 4.16 \\
\hline 2004 & $0.792(20.8 \%)$ & $0.428(57.2 \%)$ & $0.928(7.2 \%)$ & $0.704(29.6 \%)$ & 3.39 \\
\hline 2014 & $0.800(20.0 \%)$ & $0.394(60.6 \%)$ & $0.921(7.9 \%)$ & $0.736(26.4 \%)$ & 3.26 \\
\hline \multicolumn{6}{|l|}{ Middle } \\
\hline 1993-1994 & $0.794(20.6 \%)$ & $0.582(41.8 \%)$ & $0.913(8.7 \%)$ & $0.637(36.3 \%)$ & 4.10 \\
\hline 2004 & $0.782(21.8 \%)$ & $0.433(56.7 \%)$ & $0.921(7.9 \%)$ & $0.703(29.7 \%)$ & 3.34 \\
\hline 2014 & $0.790(21.0 \%)$ & $0.374(62.6 \%)$ & $0.918(8.2 \%)$ & $0.757(24.3 \%)$ & 3.14 \\
\hline \multicolumn{6}{|l|}{ Richer } \\
\hline 2004 & $0.761(23.9 \%)$ & $0.425(57.5 \%)$ & $0.904(9.6 \%)$ & $0.723(27.7 \%)$ & 3.24 \\
\hline 2014 & $0.750(25.0 \%)$ & $0.356(64.4 \%)$ & $0.916(8.4 \%)$ & $0.773(22.7 \%)$ & 2.89 \\
\hline \multicolumn{6}{|l|}{ Richest } \\
\hline 1993-1994 & $0.720(28.0 \%)$ & $0.491(50.9 \%)$ & $0.876(12.4 \%)$ & $0.703(29.7 \%)$ & 3.33 \\
\hline 2004 & $0.716(28.4 \%)$ & $0.400(60.0 \%)$ & $0.871(12.9 \%)$ & $0.757(24.3 \%)$ & 2.89 \\
\hline 2014 & $0.710(29.0 \%)$ & $0.345(65.5 \%)$ & $0.865(13.5 \%)$ & $0.783(21.7 \%)$ & 2.54 \\
\hline \multicolumn{6}{|l|}{ Total } \\
\hline 1993-1994 & $0.756(24.4 \%)$ & $0.566(43.4 \%)$ & $0.942(5.8 \%)$ & $0.649(35.1 \%)$ & 4.00 \\
\hline 2004 & $0.726(27.4 \%)$ & $0.433(56.7 \%)$ & $0.902(9.8 \%)$ & $0.715(28.5 \%)$ & 3.10 \\
\hline 2014 & $0.708(29.2 \%)$ & $0.384(61.6 \%)$ & $0.900(10.0 \%)$ & $0.754(24.6 \%)$ & 2.82 \\
\hline
\end{tabular}


$59 \%$ reduction in fertility) compared with the poorest women (51.4\% reduction in fertility) in Bangladesh.

Conversely, the effect of postpartum infecundability showed a decreasing trend over the studied time frame. The results revealed that women's wealth index had a positive effect on marriage, contraception, and induced abortion, but a negative effect on postpartum infecundability. For women in rich households, the fertility-reducing effects of marriage, contraception, and abortion were maximal, but the effect of postpartum infecundability was weakest.

Fertility Regulating Effects of Each Proximate Determinant of Fertility by Selected Socioeconomic Characteristics Table 5 shows the magnitude of the fertility-regulating effects of the proximate determinants of fertility according to the socioeconomic characteristics for the period 1993-1994 to 2014 at two different time points (1993-1994 and 2014). The fertility controlling effects of the four proximate determinants varied with the residence of the respondents (Table 5). The fertility-regulating effects of marriage and postpartum infecundability were higher in rural areas, while the effects of contraception and abortion were higher in the urban areas of Bangladesh. Simply, the results indicate that out of the 11.70 births in 1993-1994 that were inhibited in urban areas of Bangladesh, 1.82 births (or $15.56 \%$ total inhibiting effects) were due to the effect of marriage, 6.05 births (51.71\%) were because of contraception, 0.67 births $(5.73 \%)$ were because of induced abortion, and 3.15 births (26.92\%) were due to

Table 5. Fertility Regulating Effects of Proximate Determinants of Fertility According to the Socioeconomic Characteristics in Bangladesh: 1993-1994 to 2014 BDHS

\begin{tabular}{|c|c|c|c|c|c|c|c|c|c|c|}
\hline \multirow{2}{*}{ Variables } & \multicolumn{2}{|c|}{ Effect of Marriage } & \multicolumn{2}{|c|}{ Effect of Contraception } & \multicolumn{2}{|c|}{ Effect of Abortion } & \multicolumn{2}{|c|}{$\begin{array}{l}\text { Effect of Postpartum } \\
\text { Infecundability }\end{array}$} & \multicolumn{2}{|c|}{ Total effect } \\
\hline & $\begin{array}{l}\text { No. of } \\
\text { Births }\end{array}$ & $\%$ & $\begin{array}{l}\text { No. of } \\
\text { Births }\end{array}$ & $\%$ & $\begin{array}{l}\text { No. of } \\
\text { Births }\end{array}$ & $\%$ & $\begin{array}{l}\text { No. of } \\
\text { Births }\end{array}$ & $\%$ & $\begin{array}{l}\text { No. of } \\
\text { Births }\end{array}$ & $\%$ \\
\hline \multicolumn{11}{|c|}{ 1993-1994 BDHS } \\
\hline \multicolumn{11}{|l|}{ Residence } \\
\hline Urban & 1.82 & 15.56 & 6.05 & 51.71 & 0.67 & 5.73 & 3.15 & 26.92 & 11.70 & 100.0 \\
\hline Rural & 2.42 & 21.55 & 4.69 & 41.76 & 0.42 & 3.74 & 3.70 & 32.95 & 11.23 & 100.0 \\
\hline \multicolumn{11}{|l|}{ Division } \\
\hline Barisal & 1.89 & 16.67 & 5.17 & 45.59 & 0.55 & 4.85 & 3.73 & 32.89 & 11.34 & 100.0 \\
\hline Chittagong & 1.83 & 18.45 & 3.20 & 32.26 & 0.61 & 6.15 & 4.29 & 43.25 & 9.92 & 100.0 \\
\hline Dhaka & 1.97 & 17.56 & 4.85 & 43.23 & 0.78 & 6.95 & 3.62 & 32.26 & 11.22 & 100.0 \\
\hline Khulna & 1.87 & 15.70 & 6.10 & 51.22 & 0.95 & 7.98 & 2.99 & 25.10 & 11.91 & 100.0 \\
\hline Rajshahi & 1.94 & 15.99 & 5.97 & 49.22 & 0.86 & 7.09 & 3.36 & 27.70 & 12.13 & 100.0 \\
\hline Rangpur & NA & NA & NA & NA & NA & NA & NA & NA & NA & NA \\
\hline Sylhet & NA & NA & NA & NA & NA & NA & NA & NA & $\mathrm{NA}$ & NA \\
\hline \multicolumn{11}{|l|}{ Education } \\
\hline No education & 2.01 & 18.01 & 4.43 & 39.70 & 0.69 & 6.18 & 4.01 & 35.93 & 11.16 & 100.0 \\
\hline Primary & 1.91 & 17.10 & 5.05 & 45.21 & 0.84 & 7.52 & 3.36 & 30.08 & 11.17 & 100.0 \\
\hline Secondary & 2.54 & 20.91 & 5.92 & 48.72 & 0.98 & 8.07 & 2.72 & 22.39 & 12.15 & 100.0 \\
\hline \multicolumn{11}{|l|}{ Wealth Status } \\
\hline Poorest & 1.83 & 16.59 & 4.53 & 41.07 & 0.60 & 5.44 & 4.06 & 36.81 & 11.03 & 100.0 \\
\hline Poorer & 1.87 & 16.79 & 4.56 & 40.93 & 0.64 & 5.75 & 4.07 & 36.54 & 11.14 & 100.0 \\
\hline Middle & 1.97 & 17.59 & 4.61 & 41.16 & 0.78 & 6.96 & 3.84 & 34.29 & 11.20 & 100.0 \\
\hline Richer & 2.21 & 19.63 & 4.88 & 43.34 & 0.73 & 6.48 & 3.43 & 30.46 & 11.26 & 100.0 \\
\hline Richest & 2.49 & 21.52 & 5.40 & 46.67 & 1.00 & 8.64 & 2.67 & 23.08 & 11.57 & 100.0 \\
\hline \multicolumn{11}{|c|}{2014 BDHS } \\
\hline \multicolumn{11}{|l|}{ Residence } \\
\hline Urban & 2.42 & 19.19 & 7.54 & 59.79 & 0.77 & 6.11 & 1.88 & 14.91 & 12.61 & 100.0 \\
\hline Rural & 2.61 & 21.05 & 7.08 & 57.10 & 0.57 & 4.60 & 2.34 & 18.87 & 12.40 & 100.0 \\
\hline \multicolumn{11}{|l|}{ Division } \\
\hline Barisal & 2.58 & 20.72 & 7.70 & 61.85 & 0.65 & 5.22 & 1.74 & 13.98 & 12.45 & 100.0 \\
\hline Chittagong & 2.48 & 20.82 & 6.26 & 52.56 & 0.53 & 4.45 & 2.64 & 22.17 & 11.91 & 100.0 \\
\hline Dhaka & 2.45 & 19.54 & 7.12 & 56.78 & 0.63 & 5.02 & 2.34 & 18.66 & 12.54 & 100.0 \\
\hline Khulna & 2.93 & 22.91 & 7.72 & 60.36 & 0.53 & 4.14 & 1.61 & 12.59 & 12.79 & 100.0 \\
\hline Rajshahi & 2.77 & 21.44 & 8.22 & 63.62 & 0.65 & 5.03 & 1.28 & 9.91 & 12.92 & 100.0 \\
\hline Rangpur & 2.96 & 22.82 & 8.40 & 64.76 & 0.67 & 5.17 & 0.94 & 7.25 & 12.97 & 100.0 \\
\hline Sylhet & 2.18 & 19.57 & 5.59 & 50.18 & 0.72 & 6.46 & 2.65 & 23.79 & 11.14 & 100.0 \\
\hline \multicolumn{11}{|l|}{ Education } \\
\hline No education & 2.19 & 17.85 & 7.31 & 59.58 & 0.50 & 4.07 & 2.26 & 18.42 & 12.27 & 100.0 \\
\hline Primary & 2.28 & 18.30 & 7.47 & 59.95 & 0.60 & 4.82 & 2.13 & 17.09 & 12.46 & 100.0 \\
\hline Secondary & 2.56 & 20.19 & 7.51 & 59.23 & 0.64 & 5.05 & 1.96 & 15.46 & 12.68 & 100.0 \\
\hline \multicolumn{11}{|l|}{ Wealth status } \\
\hline Poorest & 1.73 & 14.59 & 7.36 & 62.06 & 0.48 & 4.05 & 2.26 & 19.06 & 11.86 & 100.0 \\
\hline Poorer & 1.74 & 14.45 & 7.27 & 60.38 & 0.64 & 5.32 & 2.39 & 19.85 & 12.04 & 100.0 \\
\hline Middle & 1.81 & 14.88 & 7.55 & 62.09 & 0.66 & 5.43 & 2.14 & 17.60 & 12.16 & 100.0 \\
\hline Richer & 2.14 & 17.24 & 7.69 & 61.97 & 0.65 & 5.24 & 1.92 & 15.47 & 12.41 & 100.0 \\
\hline Richest & 2.43 & 19.04 & 7.56 & 59.30 & 1.03 & 8.07 & 1.74 & 13.64 & 12.76 & 100.0 \\
\hline
\end{tabular}


postpartum infecundability. However, in the 2014 BDHS, out of the 12.61 births that were inhibited in urban areas of Bangladesh, 2.42 births (19.19\% total fertility-inhibiting effects) were because of marriage, 7.54 births (59.79\%) were due to the use of contraception, 0.77 births $(6.11 \%)$ were due to induced abortion, and 1.88 births (14.91\%) were due to postpartum infecundability.

A similar picture emerged when the effects of divisional variations on fertility (Table 5) were considered. In 19931994, the fertility-inhibiting effect of contraception was highest in Khulna division (51.22\%) followed by Rajshahi (49.22\%) and Barisal (45.59\%), whereas in the 2014 BDHS, the fertility-inhibiting effect of contraception was highest in Rangpur division ( 8.40 births or $64.76 \%$ ) followed by Rajshahi (63.62\%) and Khulna divisions (7.72 births or $60.36 \%)$. In the 2014 BDHS, the effect of postpartum infecundability was highest in Sylhet division (2.65 births or $23.79 \%$ ) followed by Chittagong division (22.17\%) and Dhaka division (18.66\% percent), while in 1993-1994, the decline in fertility due to postpartum infecundability was highest in Chittagong division (4.29 births or $43.25 \%$ ) followed by Barisal division (32.89\%) and Dhaka division (32.26\%). From Table 5, it can be seen that over the study period, the divisional effects of marriage, contraception, and abortion had an increasing trend, while the effect of postpartum infecundability decreased.

Marriage and contraception showed the highest fertilityinhibiting effects (decline of more than two births) among women with a secondary or higher education. Over the studied period, fertility decline due to the effects of proximate factors (marriage, contraception, and abortion) showed a rising trend, while the effect of postpartum infecundability showed a decreasing trend among women with a secondary or higher education during the studied period. The fertilityinhibiting effect of contraception was highest among women with a secondary or higher education $(48.72 \%$ in $1993-1994$, $59.23 \%$ in 2014 ) followed by those with a primary education. Thus, the lowest level of fertility among women who had completed a secondary or higher education occurred mainly because of the increased use of contraceptives.

In 1993-1994 the fertility-controlling effect of contraception was higher among women from the richest households (5.40 births or $46.67 \%)$ compared with women from the poorest households (4.53 births or $41.07 \%$ ). The fertility-regulating effects of marriage and contraception were higher in women from the richer and richest households (Table 5). However, the fertility-inhibiting effect of postpartum infecundability was higher in poor women. The effect of infecundability decreased with increases in women's economic status.

\section{Discussion}

Fertility transition is indisputably ongoing in Bangladesh. Though Bangladesh has been encountering significant decreases in fertility rates over the last two decades, this change in fertility is not equal across the country or across parts of the society.

The index of contraception had the highest fertilityinhibition effect in 1993-1994, 2004, and 2014 for both rural and urban areas of Bangladesh. In 1993-1994, the effect of contraception played a very important role in urban areas, followed by postpartum infecundability and marriage. This result is similar to that of an earlier study conducted in Bangladesh. ${ }^{4}$ In Uganda, urban living arrangements were reliably correlated with lower fertility rates compared to rural residence. ${ }^{21,25}$ Fertility levels were also higher among rural residents compared with those in urban areas. ${ }^{26}$ This consequence is identical with that shown in an earlier study conducted in Uganda, Sub-Saharan Africa, and Ethiopia, where the fertility rate was lower in urban areas. ${ }^{18,27,28}$

In rural territories, despite the fact that contraception is picking up impact over time, postpartum infecundability is still the most crucial regulator of fertility. In 2014, however, contraception was the most significant fertility-inhibiting impact, trailed by marriage, postpartum infecundability, and abortion. This study also showed that contraception had the highest fertility-regulating effect than other proximate variables in Bangladesh. Contraception rose as the most noteworthy fertility diminishing factor in Bangladesh., ${ }^{529-31}$ These findings are not consistent with those in Ethiopia, ${ }^{32-34}$ Oman, ${ }^{35}$ Malawi, ${ }^{36}$ Zambia, ${ }^{7}$ or Uganda, ${ }^{25}$ where contraception had the lowest fertility-inhibiting effects. Postpartum infecundity, on the other hand, had a predominant hindering impact on fertility.

The index of contraception is an increasingly more important determinant when considering regional variations of fertility in Bangladesh during the study period. It demonstrates a persistent expanding pattern as an inhibitor of fertility in the majority of areas in Bangladesh during the studied time. Contraception is the most fertility reducing factor in all regions of Bangladesh. ${ }^{37}$ The low fertility levels in Khulna and Rajshahi divisions are due mainly to higher rates of contraceptive use. ${ }^{38}$ Contraception has had the most significant impact in Rajshahi division compared with all other divisions. The postpartum infecundability index became an inexorably increasingly significant determinant between 1993-1994 and 2014, demonstrating a consistent pattern of fertility inhibition in the majority of divisions in Bangladesh.

The findings of the current study are in agreement with those of numerous other investigations. ${ }^{39,40}$ The effect of postpartum infecundability is highest in Chittagong division, followed by Sylhet and Dhaka divisions. From the findings of the current study, it can be observed that the divisional effect of marriage, contraception, and abortion all have increasing trends, while the effect of postpartum infecundability has decreased in all surveys in the studied period. This result is similar to that of many other studies conducted in Bangladesh. ${ }^{29,30}$

Marriage and contraception displayed the most noteworthy fertility-restraining impact (more than two births) among women who had completed at least a secondary education. Over the studied period, the effects of education level on marriage, contraception, and abortion showed an increasing trend, while the effect of postpartum infecundability showed a decreasing trend. An analysis of the proximate determinants indicated that advanced education levels are concordantly connected with lower fertility rate. ${ }^{41}$ Women's literacy has a significant negative impact on fertility transition. ${ }^{42}$ Results 
of some previous studies are in agreement with the present results, ${ }^{29,30,39,43,44}$ indicating that fertility is inversely associated with education status. ${ }^{26,30,43,45-49}$ A few other investigations, however, discovered no noteworthy effect of education on fertility. ${ }^{50}$

Marriage and contraception have better fertility-restraining impacts on women from richer and richest households. The lowest degree of fertility in the richest women is due particularly to the accelerated use of powerful contraceptive methods. The modern-day contraceptive rate for the richest women is double that of the poorest women. ${ }^{51,52}$ Younger women inside the richer wealth index are much more likely to apply modern contraceptive methods than the poorest class countries. ${ }^{42,}$ 53,54 However, postpartum infecundability has a higher fertility-restraining effect on poor women. The effect of infecundability is decreased as the economic status of women increases. This result is in agreement with the findings of several other studies conducted in Bangladesh. ${ }^{29,30,39,43,44}$ An analysis in Zambia determined that fertility was higher among women from the poorest households compared with those from the richest households. ${ }^{49}$ Women from the poorest families have nearly two times as many children as those who reside within the richest quintile. ${ }^{10}$

\section{Conclusion}

Fertility is a key component in population change. Place of residence, divisional variation, women's education, and wealth status are circuitously associated with fertility. This study determined that contraception had the greatest fertilityinhibition effect in rural and urban areas in 1993-1994, trailed by postpartum infecundability, marriage, and induced abortion. In 2014, contraception again had the highest fertility-regulating effect in urban and rural areas followed by marriage, postpartum infecundability, and abortion. Across all three studied periods, fertility continued to be high in Sylhet and Chittagong divisions. The fertility-restraining effects of marriage, contraception, and abortion showed positive associations with education level. However, postpartum infecundability displayed a negative correlation with education level. Economic status positively affects marriage, contraception, and induced abortion, while postpartum infecundability was negatively associated with economic status. In 1993-1994 and 2014, among all aspects of fertility, contraception had the highest variation on fertility-inhibiting effects of all proximate determinants in Bangladesh. However, the fertility-inhibiting effect of postpartum infecundability decreased between the period 1993-1994 and 2014. Therefore, programs need to concentrate on engendering and raising public awareness on the disadvantages of child marriage as well as on the use of effective contraceptive methods. Moreover, Chittagong division and Sylhet division require more and intensive programs on this agenda.

\section{Authors' Contributions}

IH had the original idea for this study. IH and MA contributed all the experimental work and manuscript writing. IH contributed extensively to statistical analysis. MA and IHM helped in the interpretation of data and critical revision. All
Research Highlights

\section{What Is Already Known?}

Prior to this, the main impact of the predictor determinants at the national level of Bangladesh was identified mainly in the study by applied Bongaarts' fertility model. Most studies have shown that due to the total proximity factors in Bangladesh, fertility has changed and it has not been identified any section was more attentive and reduced fertility in order to achieve transplant levels.

\section{What This Study Adds?}

This paper is mainly focuses on quantify of prime four proximate determinants according to the selected socioeconomic characteristics. The present study indicates that, the Chittagong division and the Sylhet division fertility level are higher compared to the opponent. The three principal determinants of fertility (marriage contraception and abortion) have a positive relationship with the education and socioeconomic status of women, respectively. In addition, postpartum insusceptibility indicates inverse relationship between education level and the financial status of women respectively. The present study reveals that, not only the abortion effect is not negligible, but also it has played a crucial role to reduce fertility in all selected socioeconomic status and increases trend in the case of fertility reduction.

authors read and approved the final manuscript.

\section{Conflict of Interest Disclosures}

The authors declare that they have no conflicts of interest.

\section{Ethical Approval}

This study did not require ethics committee authorization.

\section{Funding/Support}

This study did not receive any financial support.

\section{Acknowledgments}

The authors would like to express their appreciation to the National Institute of Population Research and Training (NIPORT), Bangladesh, and MEASURE Demographic and Health Survey (DHS) for allowing the use of BDHS data for the current analysis. This study received no funding support.

\section{References}

1. United Nations, Department of Economic and Social Affairs, Population Division. World Population Prospects; 2017.

2. National Institute of Population Research and Training (NIPORT), Mitra and Associates, and ICF International. Bangladesh Demographic and Health Survey 2014. Dhaka, Bangladesh, and Rockville, Maryland, USA: NIPORT, Mitra and Associates, and ICF International; 2016.

3. Cleland J. Fertility levels and trends in Bangladesh. In: Cleland J, Edward Ebanks G, Wai L, Nawab Ali M, Rashid MA, eds. Bangladesh Fertility Survey, 1989, Secondary Analysis. Dhaka: National Institute of Population Research and Training (NIPORT); 1994. 
4. Hasan MM, Islam M, Sakib S, Haq I. Influences of Proximate Determinates on Fertility Among Urban and Rural Women in Bangladesh. Dhaka Univ J Sci. 2018;66(1):49-54.

5. Islam MM, Al Mamun A, Bairagi R. Fertility and its proximate determinants in Bangladesh: evidence from the 1993/94 Demographic and Health Survey. Asia Pac Popul J. 1998;13(3):322. doi:10.18356/d2ac171b-en.

6. Caldwell JC, Barkat EK, Caldwell B, Pieris I, Caldwell P. The Bangladesh fertility decline: an interpretation. Popul Dev Rev. 1999;25(1):67-84. doi:10.1111/j.1728-4457.1999.00067.x.

7. Chola M, Michelo C. Proximate determinants of fertility in Zambia: Analysis of the 2007 Zambia Demographic and Health Survey. Int J Popul Res. 2016;2016:5236351. doi:10.1155/2016/5236351.

8. Laelago T, Habtu Y, Yohannes S. Proximate determinants of fertility in Ethiopia; an application of revised Bongaarts model. Reprod Health. 2019;16(1):1-9. doi:10.1186/s12978-019-0677-x.

9. Islam R, Islam N, Rahman M, Hossain G, Islam R. Fertility situation in Bangladesh: application of revised Bongaarts model. Sci Technol. 2015;5(2):33-38.

10. Lai SL, Tey NP. Socio-economic and proximate determinants of fertility in the Philippines. World Appl Sci J. 2014;31(10):18281836. doi:10.5829/idosi.wasj.2014.31.10.591.

11. Majumder N, Ram F. Explaining the role of proximate determinants on fertility decline among poor and non-poor in Asian countries. PLoS One. 2015;10(2):e0115441. doi:10.1371/journal. pone. 0115441 .

12. Bongaarts J. The end of the fertility transition in the developed world. Completing the Fertility Transition. Department of Economic and Social Affairs, Population Division. ESA/P/WP. 172/ Rev. 1. New York: United Nations; 2002:288-307.

13. Bongaarts J, Watkins SC. Social interactions and contemporary fertility transitions. Popul Dev Rev. 1996;22(4):639-682. doi:10.2307/2137804

14. Cleland J, Wilson C. Demand theories of the fertility transition: An iconoclastic view. Popul Stud. 1987;41(1):5-30. doi:10.1080/003 2472031000142516

15. Caldwell JC. Theory of fertility decline. New York: Academic Press; 1982.

16. Bongaarts J. A framework for analyzing the proximate determinants of fertility. Popul Dev Rev. 1978;4(1):105-132. doi:10.2307/1972149.

17. Bongaarts J, Potter R. Fertility, biology, and behavior: An analysis of the proximate determinants. Academic Press; 2013.

18. Islam MA, Sabu SP, Padmadas SS, Kabir M. Evaluation of reported induced abortion in Bangladesh: evidence from the recent DHS. In: The 132nd Annual Meeting; Washington, DC; 2004.

19. Boerma JT, Weir SS. Integrating demographic and epidemiological approaches to research on HIV/AIDS: the proximatedeterminants framework. J Infect Dis. 2005;191 Suppl 1:S61-67. doi:10.1086/425282.

20. Bongaarts J. The fertility-inhibiting effects of the intermediate fertility variables. Stud Fam Plann. 1982;13(6-7):179-189. doi:10.2307/1965445.

21. Madhavan S. An analysis of the proximate determinants of fertility in sub-Saharan Africa with a focus on induced abortion. Baltimore: Johns Hopkins University; 2014.

22. Mitra SN, Nawab Ali M, Islam S, Cross AR, Saha T. Bangladesh Demographic and Health Survey, 1993-1994. Calverton, Maryland: National Institute of Population Research and Training (NIPORT), Mitra and Associates, Macro International Inc; 1994.

23. National Institute of Population Research and Training (NIPORT), Mitra and Associates, ORC Macro. Bangladesh Demographic and Health Survey 2004. Calverton, Maryland, USA: National Institute of Population Research and Training (NIPORT), Mitra and Associates, ORC Macro; 2005.
24. Wang SX, Chen YD, Chen CH, Rochat RW, Chow LP, Rider RV. Proximate determinants of fertility and policy implications in Beijing. Stud Fam Plann. 1987;18(4):222-228. doi:10.2307/1966873.

25. Moses LYA, Kayizzi JB. Using the Bongaarts model in explaining fertility decline in Urban areas of Uganda. In: Fifth African Population Conference; Arusha; 2007.

26. Haq I. Relationship between age at marriage, education and fertility among residence of Bangladesh. Am J Soc Sci Res. 2018;4(2):33-39.

27. Mboup G, Saha T. Fertility levels trends and differentials: Demographic and health surveys, Comparative Study No. 28. Calverton, Maryland: Macro International; 1998.

28. Moultrie TA, Sayi TS, Timaeus IM. Birth intervals, postponement, and fertility decline in Africa: a new type of transition? Popul Stud (Camb). 2012;66(3):241-258. doi:10.1080/00324728.2012.7016 60.

29. Islam MM, Islam MA, Chakroborty $N$. Fertility transition in Bangladesh: understanding the role of the proximate determinants. J Biosoc Sci. 2004;36(3):351-369. doi:10.1017/ S0021932003006333.

30. Mahjabeen T, Imran Khan I, Amit Khan I. Analyzing Bongaarts model and its applications in the context of Bangladesh. 19th International Congress on Modelling and Simulation; Perth, Australia; 2011.

31. Haq I. Decomposition of the Change in Proximate Determinants and Its Impacts on Fertility in Bangladesh: An Evidence from National Surveys. Int J Math Comput Sci. 2018;4(1):8-17

32. Mekonnen W, Worku A. Determinants of fertility in rural Ethiopia: the case of Butajira Demographic Surveillance System (DSS). BMC Public Health. 2011;11:782. doi:10.1186/1471-2458-11-782.

33. Alene GD, Worku A. Estimation of the total fertility rates and proximate determinants of fertility in North and South Gondar zones, Northwest Ethiopia: An application of the Bongaarts' model. Ethiop J Health Dev. 2009;23(1):19-27. doi:10.4314/ejhd. v23i1.44833

34. Mekonnen W, Worku A. Levels and proximate determinants of fertility in Butajira District, South Central Ethiopia. Ethiop J Health Dev. 2011;25(3):184-191.

35. Islam MM, Dorvlo AS, Al-Qasmi AM. Proximate determinants of declining fertility in Oman in the 1990s. Can Stud Popul. 2012;38(3-4):133-152. doi:10.25336/P6731K.

36. Palamuleni M. Fertility decline in Malawi: an analysis of the proximate determinants. J Soc Dev Afr. 2010;25(1):9-38. doi:10.4314/jsda.v25i1.54277.

37. Kabir A, Ali R, Islam MS, Kawsar LA, Islam MA. A comparison of regional variations of fertility in Bangladesh. Int $\mathrm{Q}$ Community Health Educ. 2008;29(3):275-291. doi:10.2190/IQ.29.3.f.

38. Islam MM, Rob U, Chakroborty N. Regional variations in fertility in Bangladesh. Genus. 2003;59(3-4):103-145.

39. Islam MN, Islam MM. Biological and behavioural determinants of fertility in Bangladesh: 1975-1989. Asia Pac Popul J. 1993;8(1):318. doi:10.18356/a538a363-en.

40. Hossain F, Karim R. Determination of Total Fertility Rate of Bangladesh using Bongaarts Model. J Biom Biostat. 2013;4(5):1-4. doi:10.4172/2155-6180.1000176.

41. Rutaremwa G, Galande J, Nviiri HL, Akiror E, Jhamba T. The contribution of contraception, marriage and postpartum insusceptibility to fertility levels in Uganda: an application of the aggregate fertility model. Fertil Res Pract. 2015;1:16. doi:10.1186/ s40738-015-0009-y.

42. Drèze J, Murthi M. Fertility, education, and development: evidence from India. Popul Dev Rev. 2001;27(1):33-63. doi:10.1111/j.17284457.2001.00033.x.

43. Hailemariam T, Sebhatu A, Gebreselassie T. Components of Fertility Change in Ethiopia: Further Analysis of the 2000, 2005, and 2011 
Demographic and Health Surveys. DHS Further Analysis Reports No. 80. Calverton. Maryland, USA: ICF International; 2013.

44. Ko EY, Siddiqi K, Brannigan RE, Sabanegh ES, Jr. Empirical medical therapy for idiopathic male infertility: a survey of the American Urological Association. J Urol. 2012;187(3):973-978. doi:10.1016/j.juro.2011.10.137.

45. Shapiro D, Gebreselassie T, Strunk L. Fertility transition in subSaharan Africa: evidence from the demographic and health surveys. Minneapolis: Paper presented at the Annual Meeting of the Population Association of America; 2003

46. Adhikari R. Demographic, socio-economic, and cultural factors affecting fertility differentials in Nepal. BMC Pregnancy Childbirth. 2010;10:19. doi:10.1186/1471-2393-10-19.

47. Karakaya Ayalp E. Socioeconomic determinants on fertility rate at an aggregate level: a linear regression model for Turkish provinces. Public Knowledge Journal. 2014;6:1-6.

48. Kalule-Sabiti I. Socio-economic factors affecting fertility in Kenya. S Afr J Soc. 1992;23(2):46-52. doi:10.1080/02580144.1992.104 29816.

49. Chola M, Michelo C. Examining underlying determinants of fertility rates in Zambia: Evidence from the 2007 Zambia Demographic and Health Survey. Etude Popul Afr. 2016;30(2):2318-2327. doi:10.11564/30-2-829.
50. Mutharayappa R. Factors affecting fertility among tribals. Man \& Development. 1994;16(4):63-79.

51. Gwatkin DR, Rutstein S, Johnson K, Suliman E, Wagstaff A, Amouzou A. Socio-economic differences in health, nutrition, and population within developing countries. Washington, DC: The World Bank; 2007:287.

52. Yazbeck AS, Gwatkin DR, Wagstaff A, Qamruddin J. Why were the reaching the poor studies undertaken? In: Gwatkin DR, Wagstaff A, Yazbeck AS, eds. Reaching the poor with health, nutrition, and population services: what works, what doesn't, and why. Washington, DC: The World Bank; 2005:3-26. doi:10.1596/9780-8213-5961-7.

53. Worku AG, Tessema GA, ZelekeAA. Trends of modern contraceptive use among young married women based on the 2000, 2005, and 2011 Ethiopian Demographic and Health Surveys: a multivariate decomposition analysis. PLoS One. 2015;10(1):e0116525. doi:10.1371/journal.pone.0116525.

54. Adebowale SA, Adedini SA, Ibisomi LD, Palamuleni ME. Differential effect of wealth quintile on modern contraceptive use and fertility: evidence from Malawian women. BMC Womens Health. 2014;14(1):40. doi:10.1186/1472-6874-14-40. 